\title{
The Emotional Ecology Embodied in the Foreign Best- selling Works of "Dear John"
}

\author{
Xiao-li Zhang \\ School of Foreign Languages, Lanzhou University of Technology, Gansu Province, China
}

\begin{abstract}
Ecology is the scientific analysis and study of interactions among organisms and their environment literally. Emotional ecology, as a kind of emotional communication atmosphere, can be appreciated subtly in literary works. The interpretation of rich emotional ecology in Dear John offers a unique perspective in literary interpretative processes.
\end{abstract}

Index Terms - emotional ecology; positive emotion; negative emotion

\section{Introduction}

Life, being a kaleidoscope, with specifically short stories as cross-sections of life reflecting certain life situations in a complicated world, embodies people in certain normal life humanity. There is actually little research of emotional ecology in literary works and by far the related trials are mainly affective factors in learning and teaching, with the only direct exploration of emotional ecology concerning the cultivation of learning environment in the literature review. Zeng Yan (2008) discussed English teaching methods based on affective factors; Zhou Yinxin (2011) conducted an empirical study of affective factors in the oral teaching of Business English; Zhang Shuhuan (2011) advocated the environment construction of emotional ecology in classroom teaching.

Emotional ecology is a kind of emotional communication atmosphere in a certain culture where men and women choose their partners and friends, or the general social intercourse, by the following values, such as personal accomplishments or personal qualities. The atmosphere is sometimes as subtle as tasting a perfume, sometimes as obvious as a fly on a bald head. Words, actions, eye contacts and dresses all these details are factors constituting this atmosphere.

Complicated human emotions can be vaguely classified from different angles of observation. According to the different positive and negative directions of value changes, emotions can be divided into positive emotions and negative ones. Positive emotion is the positive value increase or negative value reduction generated in the value of the emotion, such as happiness, trust, appreciation, joy; negative emotion is the negative value increase or positive value reduction in the value of feelings, such as pain, envy, hatred, sorrow and so forth.

From a new perspective, this paper explores emotional ecology in the scroll painting unfolded in the novel so that the subtle spiritual realm can be fully appreciated.

\section{The Main Plot of the Story}

An angry rebel, John dropped out of school and enlisted in the Army, not knowing what else to do with his life--until in 2001, on vacation, he meets the girl of his dreams, Savannah, a college student on spring break. They begin falling in love with each other.

John and Savannah continue their relationship through letters, expecting to build a life together when he leaves the army. But the September 11 attacks make him reconsider the army, and he ultimately chooses to re-enlist. Over the next two years, the romance goes on, through their letters. After a time, John finds himself anxiously awaiting the next letter, but when it arrives it is a Dear John letter, informing him that she has become engaged to someone else, John burns all of Savannah's letters.

Despite being wounded and encouraged to return home, John re-enlists. After four more years and many missions, while waiting to receive orders on his unit's next deployment, John is informed that his father had a stroke. When John arrives at the hospital he learns that his father is still alive but in grave condition. Soon afterwards, his father dies.

John goes to visit Savannah and is shocked to find that she has married Tim and is living with him. He learns that she had to abandon her dream of a riding camp for kids with autism because of Tim's fight against lymphoma, and John goes with her to visit him in the hospital. Tim tells John that Savannah still loves John and she has never forgotten him. That night, Savannah asks John to stay for dinner. At the table, John asks Savannah why she did not even call him and she says it was because just hearing his voice would make her change her mind. As John goes towards the door, Savannah says "I'll see you soon then". She asks him to reply the same (like they always do) but there is silence. John could not say it back because it wouldn't have the same meaning as before. John stands at the door struggling inside to decide. Savannah asks for him to say it back once again. He replies "Goodbye, Savannah" and leaves, which leaves Savannah crushed and heartbroken. John drives away knowing the decision to let her go had killed him inside. John makes a decision to sell all of his father's coin collection to raise money, which could help Tim in his treatment. It then shows John receiving a letter from Savannah telling him that Tim died after two months and ending with "I'll see you soon then". The film then skips forward to show John as a civilian, having left the army,

Fund No.: 1313ZCX002, Humanities and Social Science Fund, 2013 LUT 
carrying his bike. He sees Savannah in a coffee shop, and they make eye contact. The last scene ends with both of them warmly hugging one another outside the coffee shop.

\section{Research Methods}

In this novel, emotional ecology can be embodied mainly with the description of the main characters with the descriptions of their utterances, gestures, eye contacts and the other related elements.

The study method of this thesis is to analyse the quantitative statistics got by means of software counting to appreciate the emotional elements constituting an emotional ecology in the novel. The structure of emotional ecology can be illustrated below in Table 1 .

Table 1 Structure of Emotional Ecology

\begin{tabular}{|c|c|c|}
\hline \multirow{8}{*}{$\begin{array}{l}\text { EMOTIONAL } \\
\text { ECOLOGY }\end{array}$} & \multirow{4}{*}{ Positive emotions } & happiness \\
\hline & & trust \\
\hline & & appreciation \\
\hline & & joy \\
\hline & \multirow{4}{*}{ Negative emotions } & pain \\
\hline & & envy \\
\hline & & sorrow \\
\hline & & hatred \\
\hline
\end{tabular}

Actually, there is no clear cut in the definition or classification of emotional ecology. The table only shows its general interpretation so that every element can be analysed statistically.

\section{Data Analysis}

\section{A. A general description}

In terms of text length, lexical density as well as other criteria, the novel is interpreted as below in Table 2 from which we can see first person reference is used the most while second person reference the least.

Table 2 General Information of the Novel

\begin{tabular}{|c|c|c|}
\hline \multirow{2}{*}{ Length } & Number of segments & 88136 \\
\cline { 2 - 3 } & Words in segments & 7758 \\
\hline \multirow{2}{*}{ Text Complexity } & Av. Word Length & 4.23 \\
\cline { 2 - 3 } & Av. Segment Length & 11.3 \\
\hline \multirow{2}{*}{ Lexical Density } & Lexemes per segment & 5.47 \\
\cline { 2 - 3 } & Lexemes \% of text & 48.22 \\
\hline \multirow{2}{*}{$\begin{array}{c}\text { Reference Density } \\
(\% \text { of tokens) }\end{array}$} & 1p reference & 7.6313 \\
\cline { 2 - 3 } & 2p reference & 1.2355 \\
\cline { 2 - 3 } & 3p reference & 5.9771 \\
\hline
\end{tabular}

The novel in a sense is an autobiography where the main male character John either reflects on himself or conveys the missing of Savannah, the main female character, or whatever. It is quite understandable that the first person reference is used the most for the sake of natural flow of his emotions.

\section{B. A detailed description of emotional ecology}

From a certain criterion, emotional ecology can be classified into positive emotions and negative ones. Specifically, positive emotions can be understood in terms of happiness, trust, appreciation and joy; negative emotions can be specified in pain, envy, sorrow and hatred.

Table 3 Detailed Description of Emotional Ecology in the Novel

\begin{tabular}{|r|c|r|}
\hline \multicolumn{1}{|c|}{ Feature } & Percent & $\mathrm{N}$ \\
\hline EMOTIONAL_ECOLOGY-TYPE & $\mathrm{N}=716$ & \\
\hline positive-emotions & $60.34 \%$ & 432 \\
\hline negative-emotions & $39.66 \%$ & 284 \\
\hline POSITIVE-EMOTIONS-TYPE & $\mathrm{N}=432$ & 31 \\
\hline happiness & $7.1 \%$ & 125 \\
\hline trust & $28.6 \%$ & 216 \\
\hline appreciation & $50.0 \%$ & 60 \\
\hline joy & $14.3 \%$ & 36 \\
\hline pain & $12.5 \%$ & 3 \\
\hline envy & $1.15 \%$ & 32 \\
\hline sorrow & $75.0 \%$ & 213 \\
\hline hatred & $11.35 \%$ & \\
\hline & & \\
\hline
\end{tabular}

From the table above, it can be shown that in the whole emotional ecology, the positive emotions dominate generally with negative emotions being indispensible in the constitution of emotional ecology. In the novel, as for the positive emotions, too much is on appreciation rather than the direct expression of happiness, which is an indication that we readers are supposed to capture the subtlety of literary works. As for negative emotions, the previous lovers are immersed in too much sorrow triggered by the retrospect with the occasionally desperate memory of the past.

\section{Conclusion}

To some extent, literary works originate from the social reality and reflect it in turn. Dear John, the love story that each of us may face, unfolds the protagonist's anger and happiness with the ups and downs of life, making us immersed in the world of his emotional ecology, with the true meaning of love being appreciated. This attempt gives a new dimension to literature interpretation activities as a new inspiration for the research on literature interpretation.

\section{References}

[1] Zhang Shuhuan. Construction of Classroom Teaching Emotional Ecological Environment to Optimize the Classroom Teaching Effectively, China Science Innovation Guide, 2011(30).

[2] Zhou Yinxin. Oral Business English Teaching in Higher Vocational Colleges Based on an Empirical Study of the Affective Factors, Journal of Nanchang Education College, 2011(07).

[3] Zeng Yan, English Teaching Method in Middle School Based on Affective Factors, Journal of Chongqing Education College, 2008(02). 